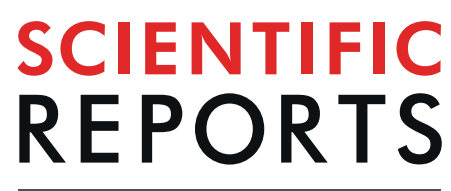

\title{
Evaluation of antifungal effect and toxicity of xanthyletin and two bacterial metabolites against Thai isolates of Pythium insidiosum
}

\author{
Kittiya Wittayapipath ${ }^{1}$, Chavi Yenjai ${ }^{2}$, Chularut Prariyachatigul ${ }^{3} \&$ Petr Hamal $^{4 *}$ \\ Pythiosis is a harmful disease caused by Pythium insidiosum, an aquatic oomycete. Therapeutic \\ protocols based on antifungal drugs are often ineffective because the cytoplasmic membrane of \\ $P$. insidiosum does not contain ergosterol. Therefore, the treatment of pythiosis is still challenging, \\ particularly making use of natural products and secondary metabolites from bacteria. In this study, \\ xanthyletin and substances obtained from Pseudomonas stutzeri ST1302 and Klebsiella pneumoniae \\ ST2501 exhibited anti-P. insidiosum activity and, moreover, xanthyletin was non-toxic against human \\ cell lines. The hyphae of $P$. insidiosum treated with these three substances exhibited lysis holes on \\ a rough surface and release of anamorphic material. Therefore, xanthyletin could be considered a \\ promising alternative agent for treating cutaneous pythiosis in the near future.
}

Pythium insidiosum is an aquatic oomycete, or fungus-like microorganism. Its morphology is similar to that of filamentous fungi but a phylogenetic analysis of this pathogen has shown a closely related to diatoms and algae than to true fungi ${ }^{1}$. P. insidiosum can infect both humans and animals through the eyes or skin wounds, causing pythiosis, an endemic disease with high morbidity and mortality rates ${ }^{2,3}$. Human pythiosis manifests clinically as cutaneous and subcutaneous, vascular, ocular or disseminated infection. The treatment includes antifungal agents, radical surgery and immunotherapy. However, these options have not always been successful and generally accepted therapeutic protocols have not yet appeared ${ }^{2,4}$. Most of the common antifungal drugs are ineffective because the cytoplasmic membrane of $P$. insidiosum does not contain ergosterol or this pathogen possesses an incomplete ergosterol biosynthetic pathway ${ }^{5}$. Therefore, the treatment of pythiosis is still challenging. Previous studies demonstrated that natural compounds from plants and secondary metabolites from microorganisms had relatively good in vitro antimicrobial activity against $P$. insidiosum ${ }^{6,7}$. Xanthyletin, a natural compound of green plants, is classified in a group of pyranocoumarins, coumarin derivatives. Antifungal activity of xanthyletin against Candida albicans, Aspergillus fumigatus and Fusarium solani as well as its anti-P. insidiosum effect have been reported ${ }^{6,8}$. Besides, its anticancer and antibacterial activity were also described ${ }^{9}$. Bacterial species belonging to the genus Pseudomonas, especially those isolated from the environment, are often used as biocontrol agents in economic crops since the pathogen excretes substances with antibacterial and antifungal activity $^{10}$. Moreover, microorganisms of the genus Klebsiella produce secondary metabolites with antibacterial and antifungal activity as well ${ }^{11}$. An in vitro study of secondary metabolites excreted from bacterial environmental strains included Pseudomonas stutzeri and Klebsiella pneumoniae from 16 strains that expressed anti-P. insidiosum activity ${ }^{7}$. However, the mechanisms of action of both xanthyletin and secondary metabolites from bacteria with anti-P. insidiosum activity remain unclear. Fibroblasts are one of the most common cell types, widely present in many structures, particularly in connective tissue and predominantly in the human dermis. Fibroblasts are of mesenchymal origin, exhibiting a spindle or stellate shape morphology. These cells play an important role in the cutaneous wound healing process ${ }^{12,13}$. As one of the clinical manifestations of human pythiosis is cutaneous and subcutaneous infections, toxicity testing of substances with anti-P. insidiosum effects on these cell lines are

\footnotetext{
${ }^{1}$ Medical Science Program, Graduate School, Faculty of Associated Medical Sciences, Centre for Research and Development of Medical Diagnosis Laboratories, Khon Kaen University, Khon Kaen, Thailand. ${ }^{2}$ Department of Chemistry, Faculty of Science, Khon Kaen University, Khon Kaen, Thailand. ${ }^{3}$ Department of Clinical Microbiology, Faculty of Associated Medical Sciences, Centre for Research and Development of Medical Diagnosis Laboratories, Khon Kaen University, Khon Kaen, Thailand. 'Department of Microbiology, Faculty of Medicine and Dentistry, Palacky University Olomouc, Hnevotinska 3, 77515, Olomouc, Czech Republic. *email: petr.hamal@fnol.cz
} 


\begin{tabular}{|c|c|c|c|c|c|c|c|c|c|c|c|c|c|c|}
\hline \multirow[b]{3}{*}{ Substances } & \multirow[b]{3}{*}{$\begin{array}{l}\text { Fraction } \\
\text { number }\end{array}$} & \multirow[b]{3}{*}{ Characteristics } & \multirow{3}{*}{$\begin{array}{l}\text { Screening for } \\
\text { anti-P. insidiosum } \\
\text { activity by the disc } \\
\text { diffusion method }\end{array}$} & \multicolumn{10}{|c|}{ Minimum fungicidal concentrations $(\mathrm{mg} / \mathrm{mL})$ against $P$. insidiosum strains } & \multirow[b]{3}{*}{$\begin{array}{l}\text { Disseminated } \\
\text { MCC29 }\end{array}$} \\
\hline & & & & \multicolumn{6}{|c|}{ Vascular } & \multicolumn{4}{|c|}{ Ocular } & \\
\hline & & & & \begin{tabular}{|l|} 
SIMI- \\
$2989-42$ \\
\end{tabular} & \begin{tabular}{|l|} 
SIMI- \\
7873
\end{tabular} & \begin{tabular}{|l|} 
SIMI- \\
7874
\end{tabular} & \begin{tabular}{|l|} 
SIMI- \\
8659
\end{tabular} & \begin{tabular}{|l} 
SIMI- \\
8727
\end{tabular} & MCC5 & \begin{tabular}{|l|} 
SIMI- \\
6666
\end{tabular} & \begin{tabular}{|l|} 
SIMI- \\
18093 \\
\end{tabular} & \begin{tabular}{|l|} 
SIMI- \\
322-37
\end{tabular} & \begin{tabular}{|l|} 
SIMI- \\
9743
\end{tabular} & \\
\hline \multirow{5}{*}{$\begin{array}{l}\text { The crude extract } \\
\text { from Klebsiella } \\
\text { pneumoniae ST2501 }\end{array}$} & 1 & Brow semisolid & Active & 3.125 & 3.125 & 3.125 & 1.563 & 1.563 & 1.563 & 3.125 & 1.563 & 1.563 & 1.563 & 1.563 \\
\hline & 2 & Brown oil & Active & - & - & - & - & - & - & - & - & - & - & - \\
\hline & 3 & Brown solid & Active & - & - & - & - & - & - & - & - & - & - & - \\
\hline & \begin{tabular}{|l|}
4 \\
\end{tabular} & Black oil & Active & - & - & - & - & - & - & - & - & - & - & - \\
\hline & 5 & Black semisolid & Inactive & - & - & - & - & - & - & - & - & - & - & - \\
\hline \multirow{14}{*}{$\begin{array}{l}\text { The crude extract } \\
\text { from Pseudomonas } \\
\text { stutzeri ST1302 }\end{array}$} & 1 & Yellow oil & Inactive & - & - & - & - & - & - & - & - & - & - & - \\
\hline & 2 & Orange oil & Inactive & - & - & - & - & - & - & - & - & - & - & - \\
\hline & 3 & Deep yellow solid & Active & - & - & - & - & - & - & - & - & - & - & - \\
\hline & 4 & Deep yellow solid & Active & - & - & - & - & - & - & - & - & - & - & - \\
\hline & 5 & Deep yellow solid & Inactive & - & - & - & - & - & - & - & - & - & - & - \\
\hline & 6 & Yellow solid & Active & 3.125 & 3.125 & 3.125 & 3.125 & 3.125 & 3.125 & 3.125 & 3.125 & 3.125 & 3.125 & 3.125 \\
\hline & 7 & Deep yellow solid & Inactive & - & - & - & - & - & - & - & - & - & - & - \\
\hline & 8 & Brown oil & Inactive & - & - & - & - & - & - & - & - & - & - & - \\
\hline & 9 & Deep yellow solid & Active & - & - & - & - & - & - & - & - & - & - & - \\
\hline & 10 & White solid & Inactive & - & - & - & - & - & - & - & - & - & - & - \\
\hline & 11 & White solid & Inactive & - & - & - & - & - & - & - & - & - & - & - \\
\hline & 12 & Brown oil & Active & - & - & - & - & - & - & - & - & - & - & - \\
\hline & 13 & Brown oil & Inactive & - & - & - & - & - & - & - & - & - & - & - \\
\hline & 14 & Brown oil & Inactive & - & - & - & - & - & - & - & - & - & - & - \\
\hline Xanthyletin & - & White powder & Active & 0.003 & 0.003 & 0.003 & 0.003 & 0.003 & 0.003 & 0.003 & 0.003 & \begin{tabular}{|l|}
0.003 \\
\end{tabular} & 0.003 & \begin{tabular}{|l|}
0.003 \\
\end{tabular} \\
\hline
\end{tabular}

Table 1. The characteristics of fractions of the crude extracts from bacteria, screening for anti-Pythium insidiosum activity and the minimum fungicidal concentrations of anti-P. insidiosum substances against 11 $P$. insidiosum strains isolated from pythiosis patients in Thailand.

important in terms of their safety in the treatment of pythiosis. Therefore, this study evaluated the anti- $P$. insidiosum effect of xanthyletin and secondary metabolites from P. stutzeri and K. pneumoniae on P. insidiosum by broth dilution susceptibility testing and scanning electron microscopy (SEM). The toxicity of these substances to the cell lines prepared from normal human dermal fibroblast (NHDF) cells was also assessed.

\section{Results}

Crude extracts and fractions from $P$. stutzeri ST1302 and $K$. pneumoniae ST2501 and their anti-P. insidiosum activity. Crude extracts from P. stutzeri ST1302 (brown liquid) and K. pneumoniae ST2501 (dark brown liquid) showed anti-P. insidiosum activity as screened by the disc diffusion method. After that, the crude extracts were fractionated by activity-guided separation liquid column chromatography. The crude extracts from K. pneumoniae ST2501 were divided into 5 fractions; fraction number 1 was brown semisolid, fraction number 2 was brown oil, fraction number 3 was brown solid, fraction number 4 was black oil and fraction number 5 was black semisolid. The crude extracts from P. stutzeri ST1302 were divided into 14 fractions; fraction no. 1 was yellow oil, fraction no. 2 was orange oil, fractions no. 3, 4, 5, 7 and 9 were deep yellow solid, fraction no. 6 was yellow solid, fractions no. 8,12,13 and 14 were brown oil, and fractions no. 10 and 11 were white solid. Fractions no. 1 to 4 of the crude extracts from K. pneumoniae ST2501 and fractions no. 3, 4, 6, 9 and 12 of the crude extracts from $P$. stutzeri ST1302 exhibited anti- $P$. insidiosum activity (Table 1 ). The strongest anti- $P$. insidiosum activity (the largest inhibition zone) was exhibited by fraction no. 6 of the crude extract from $P$. stutzeri (Fig. 1) eluted with $20 \%$ methanol in dichloromethane and fraction no. 1 of the crude extract from K. pneumoniae eluted with $100 \%$ dichloromethane. For further testing, only two fractions mentioned above with the strongest anti-P. insidiosum activity together with xanthyletin were chosen.

Minimum fungicidal concentrations (MFCs) determined by broth dilution susceptibility testing. The MFCs of xanthyletin, fraction no. 1 of the crude extract from K. pneumoniae ST2501, and fraction no. 6 of the crude extract from P. stutzeri ST1302 against 11 strains of $P$. insidiosum isolated from human pythiosis in Thailand were $0.003,1.563-3.125$, and $3.125 \mathrm{mg} / \mathrm{mL}$, respectively (Table 1 ).

Hyphal morphology evaluated by scanning electron microscopy. Figure 2 shows morphological hyphae of $P$. insidiosum (negative control; $P$. insidiosum survival) and hyphae changes when $P$. insidiosum was treated with thimerosal (positive control; $P$. insidiosum death) and treated with three anti-P. insidiosum substances. The negative control showed cylindrical hyphae with a smooth surface (Fig. 2A). Hyphae from the positive control were with a rough surface and high amount of anamorphic material released from the organism (Fig. 2B). Morphology of hyphae treated with three anti-P. insidiosum substances including xanthyletin (Fig. 2C), fraction no. 6 of the crude extract from P. stutzeri ST1302 (Fig. 2D) and fraction no. 1 of the crude extract from K. pneumoniae ST2501 (Fig. 2E) exhibited lysis holes on a rough surface and anamorphic material released from hyphae. 


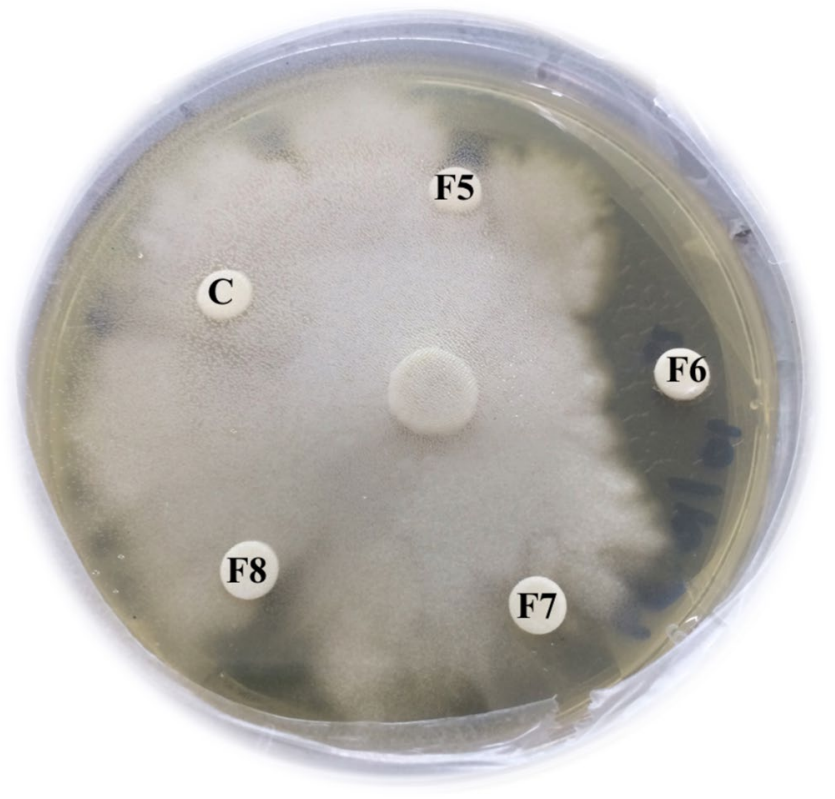

Figure 1. Screening for anti-Pythium insidiosum activity of fractions no. 5, 6, 7 and 8 of the crude extract from Pseudomonas stutzeri ST1302 by the disc diffusion method. The inhibition zone was found around fraction no. 6 which means it had anti-P. insidiosum activity. $\mathrm{C}=$ control disc (dichloromethane), $\mathrm{F}=$ fraction number.

Cytotoxicity assay. The toxicity testing of xanthyletin and extracts from P. stutzeri ST1302 and K. pneumoniae ST2501 covered the whole ranges of dilutions tested for MFC determination by the broth dilution method. The effect of anti-P. insidiosum substances on NHDF cells was dose-dependent. The IC50 of xanthyletin, fraction no. 6 of the crude extract from P. stutzeri ST1302 and fraction no. 1 of the crude extract from K. pneumoniae ST2501 were $0.11,4.69$, and $7.81 \mathrm{mg} / \mathrm{mL}$, respectively (Fig. 3). Further, at the MFC of xanthyletin, NHDF cells showed more than $90 \%$ viability, compared to only $55 \%$ and $70 \%$ viability in case of the MFCs of the tested fractions from P. stutzeri and K. pneumoniae, respectively.

\section{Discussion}

It is well known that the therapy of pythiosis has posed a challenge in recent decades as the current treatment options are highly variable and often lead to failure ${ }^{14}$. Therefore, many studies have searched for antimicrobial agents, natural compounds or secondary metabolites from microorganisms against $P$. insidiosum and results of in vitro testing are quite promising ${ }^{6,715-21}$. The present study evaluated antimicrobial effects against $P$. insidiosum of xanthyletin and two fractions of the crude extracts from P. stutzeri ST1302 and K. pneumoniae ST2501. The MFC results of fraction no. 1 from the crude extract from K. pneumoniae against $P$. insidiosum strains SIMI-6666, SIMI-2989-42, SIMI-7873 and SIMI-7874 at higher concentrations than the other strains correlated with the previous study ${ }^{21}$. Xanthyletin showed the best anti-P. insidiosum activity and the MFC of $0.003 \mathrm{mg} / \mathrm{mL}$ was well correlated with compound 5 from Scaevola taccada fruits exhibiting good anti-P. insidiosum activity (the minimum inhibitory concentration $0.005 \mathrm{mg} / \mathrm{mL})^{6}$. SEM analysis of $P$. insidiosum treated with anti-P. insidiosum substances revealed lysis holes on a rough surface and anamorphic material released from hyphae, suggesting effects on protein composition in the cell wall or cell membrane of this oomycete. Our previous study using Fourier transform infrared spectroscopy found anti-P. insidiosum activity of xanthyletin and secondary metabolites from P. stutzeri ST1302 and K. pneumoniae ST2501, characterized by clearly changed proteins in P. insidiosum ${ }^{21}$. Thimerosal is a well-known compound used as a preservative in various cosmetics, vaccines and drug products because of its bactericidal and antifungal properties including anti-P. insidiosum activity. However, it is toxic to humans, causing mortality in the fetus, birth defects and neurodevelopmental disorders as evidenced by a case of a pregnant woman who received a vaccine preserved with thimerosal. Besides, cellular apoptosis and abnormal functions of T- and B-cells that affected cytokine production, cell growth and proliferation following chronic exposure to low levels of methyl mercury have also been reported ${ }^{22,23}$. Recently, we used $0.02 \%(\mathrm{w} / \mathrm{v})$ thimerosal as a positive control because it can kill $P$. insidiosum although this amount is not suitable for use in humans and animals. The mechanism of its action is not fully understood yet and we suspected it to be related to interactions with some proteins in $P$. insidiosum leading to the death of the microorganism ${ }^{21}$. Xanthyletin is a pyranocoumarin that has been shown to be cytotoxic in vitro against tumor cells such as Caco-2, HCT-8 and HEp-2 cell lines using an MTT assay $^{24}$. Moreover, xanthyletin showed cytotoxic activity against human cancer HeLa cells without toxicity to normal cells ${ }^{9}$. The NHDF cell culture was selected for cytotoxicity assay as these cells are a common part of the human dermis and toxic effects of drugs on them are undesirable. Moreover, one of the important clinical signs of human pythiosis is skin damage. In the present study, xanthyletin at $0.003 \mathrm{mg} / \mathrm{mL}$ showed the best anti-P. insidiosum activity and exhibited low toxicity for NHDF cells. However, this study evaluated anti-P. insidiosum activity against only 11 strains of $P$. insidiosum isolated from pythiosis patients in Thailand. Therefore, further studies 

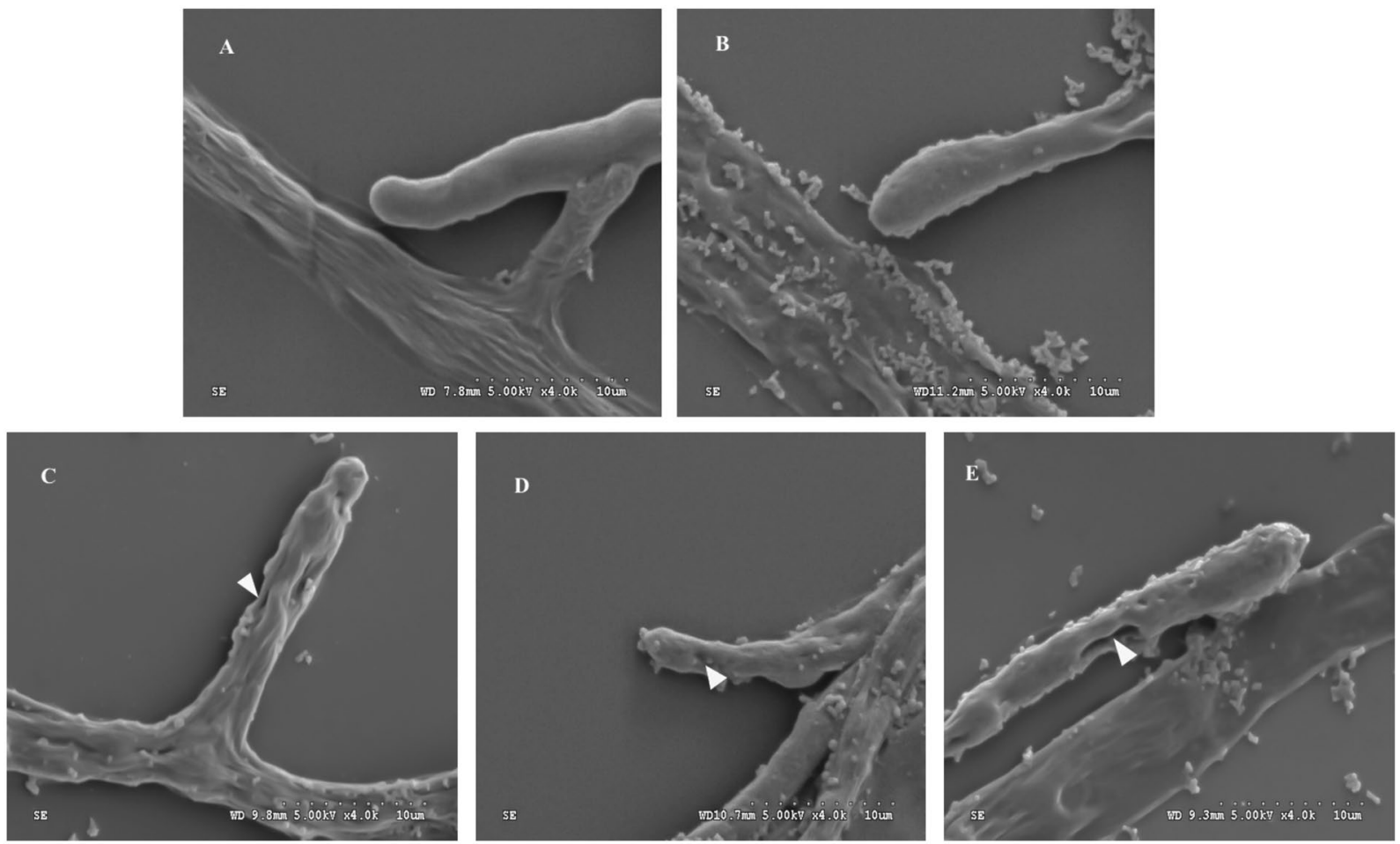

Figure 2. Scanning electron microscopy of Pythium insidiosum. (A) Negative control (P. insidiosum survival): cylindrical and a smooth surface of hyphae. (B) Positive control (P. insidiosum treated by thimerosal): a rough surface and high amount of released anamorphic material. (C-E) P. insidiosum treated with three anti-P. insidiosum substances; all pathogens exhibited lysis holes (head arrows) on a rough surface and released anamorphic material: (C) effect of xanthyletin, (D) effect of fraction no. 6 of the crude extract from Pseudomonas stutzeri ST1302, (E) effect of fraction no. 1 of the crude extract from Klebsiella pneumoniae ST2501.

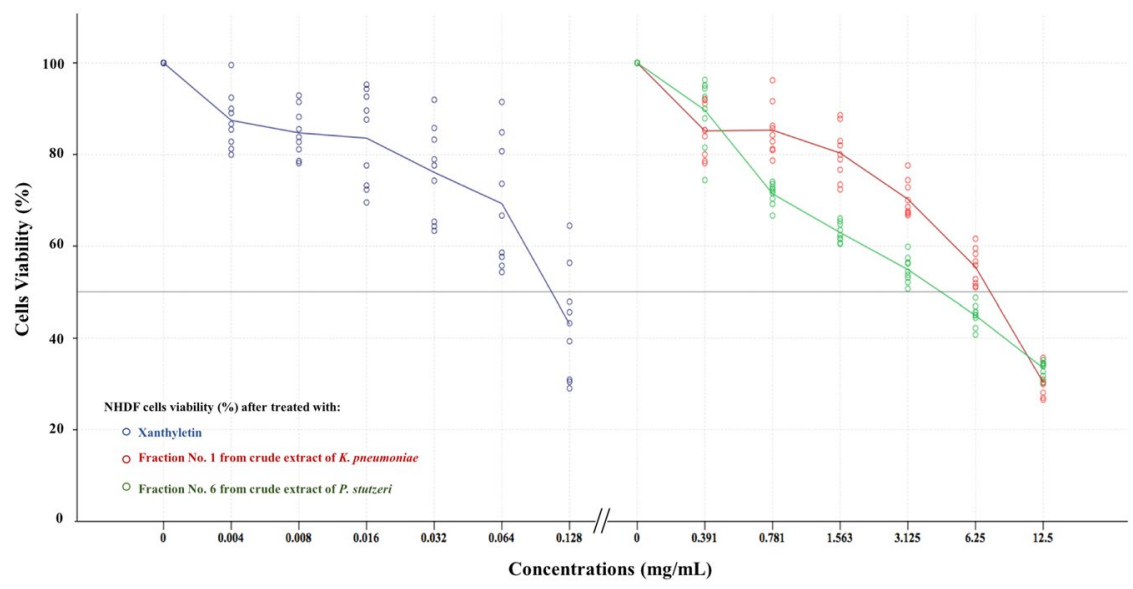

Figure 3. Survival rates of normal human dermal fibroblast cells against various concentrations of xanthyletin, fraction no. 1 of the crude extract from Klebsiella pneumoniae ST2501 and fraction no. 6 of the crude extract from Pseudomonas stutzeri ST1302 after $24 \mathrm{~h}$.

on geographically and genetically diverse $P$. insidiosum strains and anti- $P$. insidiosum activity against pythiosis in animal models should be conducted to confirm the properties of these anti-P. insidiosum substances.

\section{Conclusion}

As seen from the evaluation of anti-P. insidiosum effects and toxicity of xanthyletin and secondary metabolites from P. stutzeri ST1302 and K. pneumoniae ST2501, xanthyletin showed excellent anti-P. insidiosum activity as well as the lowest toxic effects in vitro on NHDF cells. Therefore, it could be considered a promising alternative agent for treating cutaneous pythiosis in the near future. 


\section{Material and Methods}

Microorganisms. P. insidiosum isolates $(\mathrm{n}=11)$ from human pythiosis were identified by molecular analysis in a study by Chaiprasert et al. ${ }^{25}$. The cultures were maintained on Sabouraud Dextrose Agar (SDA; Himedia) at room temperature and subcultured once a month. According to a study by Thongsri et al., they were rechecked by their morphology on the SDA at $25^{\circ} \mathrm{C}$, microscopically by detection of perpendicular sparsely septate hyphae and induced zoospore formation and by PCR identification ${ }^{7}$.

Pseudomonas stutzeri ST1302 and Klebsiella pneumoniae ST2501 which produced anti-P. insidiosum substances were isolated from a water sampling area around Khon Kaen University and identified biochemically using the VITEK 2 system (bioMérieux) ${ }^{7}$. They were stored in 10\% Oxoid Skim Milk Powder (Thermo Fisher Scientific) solution with $15 \%$ glycerol at $-20^{\circ} \mathrm{C}$.

Substances. Xanthyletin $\left(\mathrm{C}_{14} \mathrm{H}_{12} \mathrm{O}_{3}\right)$. It was obtained as a powder (purity 98\%, molecular weight 228.24) from ChemFaces (Wuhan).

Preparation and fractionation of crude extracts from $P$. stutzeri and $K$. pneumonia. The inoculations from P. stutzeri ST1302 and K. pneumoniae ST2501 were prepared according to McFarland Standard No.1 $\left(3 \times 10^{8} \mathrm{CFU} / \mathrm{mL}\right)$ in saline; $700 \mu \mathrm{L}$ of this concentration were inoculated into $700 \mathrm{~mL}$ of Brain Heart Infusion broth (BHI; Himedia) and incubated in a rotary shaker $\left(200 \mathrm{rpm}, 37^{\circ} \mathrm{C}\right)$ for 3 days. Each culture broth was then centrifuged and the supernatant was filtered through a membrane filter (Millipore). The cell-free filtrate was concentrated ten-fold in a rotary evaporator (Rotavapor R-210, Büchi) and mixed three times with a two-fold volume of dichloromethane (Thermo Fisher Scientific) in case of P. stutzeri or with ethyl acetate (Thermo Fisher Scientific) in case of $K$. pneumoniae. Both dichloromethane and ethyl acetate layers were dried with anhydrous $\mathrm{Na}_{2} \mathrm{SO}_{4}$ (Merck) and concentrated in a rotary evaporator. Then the crude extracts were fractionated by activity-guided separation liquid column chromatography using a protocol described by Wittayapipath et al. ${ }^{21}$.

Screening for anti-P. insidiosum activity by the disc diffusion method. Xanthyletin and the crude extracts from $P$. stutzeri and $K$. pneumoniae were tested for anti-P. insidiosum activity using the disc diffusion method. Stock solutions of each testing solution were prepared as $500 \mathrm{mg} / \mathrm{mL}$. Paper discs $(6 \mathrm{~mm}$ in diameter; Gibthai, Thailand) were placed onto SDA plates with $P$. insidiosum aged 2 days grown on the plates. Twenty microliters of testing solutions were applied to the discs (dichloromethane and ethyl acetate were used as controls) and then the testing plates were stored at room temperature for $2 \mathrm{~h}$ in a laminar flow biosafety cabinet to test the solution diffusion. Subsequently, they were incubated at $37^{\circ} \mathrm{C}$ for 3,6 and 9 days and inhibition zones were measured when the growth of $P$. insidiosum reached the control discs ${ }^{21}$.

Broth dilution susceptibility testing. The method by Trolezi et al. was used with some modifications ${ }^{20}$. Briefly, blocks measuring $5 \mathrm{~mm}$ in diameter were cut out from SDA plates with $P$. insidiosum cultures with a cork borer. These mycelia-containing blocks were transferred into $1.95 \mathrm{~mL}$ of Sabouraud Dextrose Broth (SDB; Himedia) and incubated at $37^{\circ} \mathrm{C}$ for 3 days. Dilutions of xanthyletin were prepared from 0.100 to $0.001 \mathrm{mg} / \mathrm{mL}$, dilutions of $P$. stutzeri ST1302 and K. pneumoniae ST2501 crude extracts from 12.5 to $0.1 \mathrm{mg} / \mathrm{mL}$ by double dilution. Each $50 \mu \mathrm{L}$ of diluted testing solutions were added to the cultures and incubated at $37^{\circ} \mathrm{C}$ for $24 \mathrm{~h}$. A P. insidiosum block in $2 \mathrm{~mL}$ of SDB was incubated at $37^{\circ} \mathrm{C}$ for 4 days as a growth control. After expiration of the incubation time, the $P$. insidiosum agar blocks with mycelium were placed on SDA plates and incubated at $37^{\circ} \mathrm{C}$ for 3,6 and 9 days (depending on the growth speed) to evaluate the hyphal growth and determine the minimum fungicidal concentrations (MFCs). The MFCs were assessed as the lowest concentration of the solution without any apparent hyphal growth. All tests were performed in triplicate.

Scanning electron microscopy of the hyphal morphology. The protocols described by Trolezi et al. ${ }^{20}$ and Mendoza et al. ${ }^{3}$ were followed with some modifications. For SEM analysis, hyphae in blocks from each testing solution evaluated as MFCs were selected. P. insidiosum hyphal fragments from the growth control in broth dilution susceptibility testing served as a negative control, that is the agent survived. By contrast, $P$. insidiosum hyphal fragments treated with $0.02 \%(\mathrm{w} / \mathrm{v})$ thimerosal (Sigma-Aldrich) were used as a positive control. Thimerosal is well known as a preservative in various cosmetics, vaccines and drug products to prevent harmful contamination with microorganism. Therefore, thimerosal completely killing P. insidiosum was used as a positive control in this study. Hyphal fragments were collected and washed three times in $0.1 \mathrm{M}$ phosphate buffer solution (PBS). Then, they were fixed in $2.5 \%$ glutaraldehyde (Merck) in $0.1 \mathrm{M} \mathrm{PBS}$ at $4{ }^{\circ} \mathrm{C}$ for $1 \mathrm{~h}$ and washed in the same buffer. Subsequently, the samples were dehydrated with a graded ethanol series. The Emitech K500X sputter coater (Quorum Technologies) was used for gold sputtering of SEM samples. Finally, the hyphal morphology was evaluated by the S-3000N scanning electron microscope (Hitachi).

Cytotoxicity assay. Xanthyletin and two anti-P. insidiosum substances from P. stutzeri ST1302 and K. pneumoniae ST2501 were evaluated for cytotoxicity using NHDF cell lines (Promocell). A colorimetric assay with 3-(4,5-dimethylthiazol-2-yl)-2,5-diphenyltetrazolium bromide (MTT) was applied to investigate the cytotoxicity ${ }^{26,27}$. Briefly, NHDF cell lines were counted with the Neubauer hemocytometer using trypan blue solution $\left(10^{4}\right.$ cells; $100 \mu \mathrm{L} /$ well). Then, the cells were cultured in the wells of 96 -well flat-bottom microplates (Thermo Fisher Scientific) containing $100 \mu \mathrm{L}$ of Dulbecco's modified Eagle's medium (Gibco) supplemented with $10 \%$ fetal bovine serum (Gibco) and $1 \%$ solution of antibiotics (penicillin and streptomycin; Gibco) at $37^{\circ} \mathrm{C}$ with $5 \% \mathrm{CO}_{2}$ and $95 \%$ humidity for $24 \mathrm{~h}$. Subsequently, $100 \mu \mathrm{L}$ of each anti-P. insidiosum substance double diluted with fresh medium was added to each well with the final concentrations in the wells ranging from 0.125 to $0.004 \mathrm{mg} / \mathrm{mL}$ in case of xanthyletin and from 12.5 to $0.391 \mathrm{mg} / \mathrm{mL}$ in case of both secondary metabolites from P. stutzeri and 
K. pneumoniae. The plates were then incubated under the same conditions. Further, the solutions in the wells were carefully discarded and cells were washed with PBS. Then, the MTT solution $(0.5 \mathrm{mg} / \mathrm{mL}$ in PBS, Invitrogen) was added at an amount of $100 \mu \mathrm{L}$ each into the wells and the mixture was kept at $37^{\circ} \mathrm{C}$ with $5 \% \mathrm{CO}_{2}$ and $95 \%$ humidity for $4 \mathrm{~h}$. After removal of the supernatant, the formazan crystals were dissolved by adding $100 \mu \mathrm{L}$ of dimethyl sulfoxide per well and the absorbance was determined at a wavelength of $570 \mathrm{~nm}$. The experiment was performed in triplicate and repeated three times under the same conditions. The rate of cytotoxicity was determined using the following formula:

$$
\text { Cell viability }(\%)=(\text { absorbance of treated cells/absorbance of control cells }) \times 100 \text {. }
$$

Additionally, the half-maximal inhibitory concentration (IC50) was measured.

Received: 12 November 2019; Accepted: 19 February 2020;

Published online: 11 March 2020

\section{References}

1. Gaastra, W. et al. Pythium insidiosum: an overview. Vet. Microbiol. 146, 1-16 (2010).

2. De Cock, A. W., Mendoza, L., Padhye, A. A., Ajello, L. \& Kaufman, L. Pythium insidiosum sp. nov., the etiologic agent of pythiosis. J. Clin. Microbiol. 25, 344-349 (1987).

3. Mendoza, L., Hernandez, F. \& Ajello, L. Life cycle of the human and animal oomycete pathogen Pythium insidiosum. J. Clin. Microbiol. 31, 2967-2973 (1993).

4. Thianprasit, M., Chaiprasert, A. \& Imwidthaya, P. Human pythiosis. Curr. Top. Med. Mycol. 7, 43-54 (1996).

5. Mendoza, L. \& Newton, J. C. Immunology and immunotherapy of the infections caused by Pythium insidiosum. Med. Mycol. 43, 477-486 (2005).

6. Suthiwong, J., Thongsri, Y. \& Yenjai, C. A new furanocoumarin from the fruits of Scaevola taccada and antifungal activity against Pythium insidiosum. Nat. Prod. Res. 31, 453-459 (2017).

7. Thongsri, Y. et al. Detection of diketopiperazine and pyrrolnitrin, compounds with anti-Pythium insidiosum activity, in a Pseudomonas stutzeri environmental strain. Biomed. Pap. Med. Fac. Univ. Palacky. Olomouc Czech Repub. 158, 378-383 (2014).

8. Montagner, C. et al. Antifungal activity of coumarins. Z. Naturforsch C. J. Biosci. 63, 21-28 (2008).

9. Ndendoung Tatsimo, S. J., Marc Lamshöft, J.-D.-D. T., Mouafo, FerdinandTalontsi, Lannang, AlainMeli, Sarkar, Prodipta \& Prasanta Kumar Bag, M. S. LC-MS guided isolation of antibacterial and cytotoxic constituents from Clausena anisata. Medicinal Chem. Res. 24, 12 (2015).

10. Leon, M. et al. Antifungal activity of selected indigenous pseudomonas and bacillus from the soybean rhizosphere. Int. J. Microbiol. 2009, 572049 (2009).

11. Al-Rubaye, A. F. \& Hameed, K. M. IH. Characterization of antifungal secondary metabolites produced by Klebsiella pneumoniae and screening of its chemical compounds using GC-MS. Int. J. Curr. Pharm. Rev. Res. 8, 8 (2017).

12. Tracy, L. E., Minasian, R. A. \& Caterson, E. J. Extracellular Matrix and Dermal Fibroblast Function in the Healing Wound. Adv. Wound Care 5, 119-136 (2016).

13. Dick, M.K., Miao, J.H. \& Limaiem, F. in StatPearls (Treasure Island (FL); 2020).

14. Hilton, R. E., Tepedino, K., Glenn, C. J. \& Merkel, K. L. Swamp cancer: a case of human pythiosis and review of the literature. Br. J. Dermatol. 175, 394-397 (2016).

15. De Souza Silveira Valente, J. et al. In vitro anti-Pythium insidiosum activity of biogenic silver nanoparticles. Med Mycol (2018).

16. Loreto, E. S., Tondolo, J. S. M., Santurio, J. M. \& Alves, S. H. Screening of antibacterial drugs for antimicrobial activity against Pythium insidiosum. Med. Mycol. 57, 523-525 (2019).

17. Araujo, M. J., Bosco, S. M. \& Sforcin, J. M. Pythium insidiosum: inhibitory effects of propolis and geopropolis on hyphal growth. Braz. J. Microbiol. 47, 863-869 (2016).

18. De Souza Silveira Valente, J. et al. In Vitro Activity of Melaleuca alternifolia (Tea Tree) in Its Free Oil and Nanoemulsion Formulations Against Pythium insidiosum. Mycopathologia 181, 865-869 (2016).

19. De Souza Silveira Valente, J. et al. In Vitro Susceptibility of Pythium insidiosum to Melaleuca alternifolia, Mentha piperita and Origanum vulgare Essential Oils Combinations. Mycopathologia 181, 617-622 (2016).

20. Trolezi, R. et al. Stryphnodendron adstringens and purified tannin on Pythium insidiosum: in vitro and in vivo studies. Ann. Clin. Microbiol. Antimicrob. 16, 7 (2017).

21. Wittayapipath, K. et al. Analysis of xanthyletin and secondary metabolites from Pseudomonas stutzeri ST1302 and Klebsiella pneumoniae ST2501 against Pythium insidiosum. BMC Microbiol. 19, 78 (2019).

22. Santos, J. C. N. et al. Thimerosal changes protein conformation and increase the rate of fibrillation in physiological conditions: Spectroscopic studies using bovine serum albumin (BSA). Int. J. Biol. Macromol. 113, 1032-1040 (2018).

23. Geier, D. A. et al. Thimerosal: clinical, epidemiologic and biochemical studies. Clin. Chim. Acta 444, 212-220 (2015).

24. Montagner, C. et al. In Vitro Cytotoxic Screening of Coumarins. Lat. Am. J. Pharm. 30, 1669-1674 (2011).

25. Chaiprasert, A. et al. Pythium insidiosum Thai isolates: molecular phylogenetic analysis. Asian Biomed. 3, 623-633 (2009).

26. Mosmann, T. Rapid colorimetric assay for cellular growth and survival: application to proliferation and cytotoxicity assays. J. Immunol. Methods 65, 55-63 (1983).

27. Riss, T. L. et al. in Assay Guidance Manual. (eds. G.S. Sittampalam et al.) (Bethesda (MD); 2004).

\section{Acknowledgements}

This research was supported by the Thailand Research Fund (TRF) through the Royal Golden Jubilee Ph.D. Program (Grant no. PHD/0174/2556). The authors are grateful to the Centre for Research and Development of the Medical Diagnostic Laboratories, Faculty of Associated Medical Sciences, Khon Kaen University, Khon Kaen, Thailand and Faculty of Dentistry, Khon Kaen University, Khon Kaen, Thailand for using its laboratory facility.

\section{Author contributions}

K.W. carried out all experiments, data analysis, and manuscript writing. P.H. and C.P. participated in the design of the study and in the manuscript writing. C.Y. collaborated in separation of crude extract, in vitro studies and manuscript writing. All authors have read and approved the final manuscript.

\section{Competing interests}

The authors declare no competing interests. 
Additional information

Correspondence and requests for materials should be addressed to P.H.

Reprints and permissions information is available at www.nature.com/reprints.

Publisher's note Springer Nature remains neutral with regard to jurisdictional claims in published maps and institutional affiliations.

(c) (i) Open Access This article is licensed under a Creative Commons Attribution 4.0 International License, which permits use, sharing, adaptation, distribution and reproduction in any medium or format, as long as you give appropriate credit to the original author(s) and the source, provide a link to the Creative Commons license, and indicate if changes were made. The images or other third party material in this article are included in the article's Creative Commons license, unless indicated otherwise in a credit line to the material. If material is not included in the article's Creative Commons license and your intended use is not permitted by statutory regulation or exceeds the permitted use, you will need to obtain permission directly from the copyright holder. To view a copy of this license, visit http://creativecommons.org/licenses/by/4.0/.

(C) The Author(s) 2020 